\title{
Evaluation of hyperoxia-induced hypercapnia in obese patients after cardiac surgery: a randomized crossover comparison of conservative and liberal oxygen administration Évaluation de l'hypercapnie induite par hyperoxie chez des patients obèses après une chirurgie cardiaque: comparaison avec devis croisé d'une administration d'oxygène conservatrice $v s$ libérale
}

\author{
Marie-Hélène Denault, MD (D) - Carolanne Ruel, MD • Mathieu Simon, MD • \\ Pierre-Alexandre Bouchard, RT $\cdot$ Serge Simard, MSc $\cdot$ François Lellouche, PhD
}

Received: 10 April 2019/Revised: 26 July 2019/Accepted: 4 August 2019/Published online: 24 October 2019

(C) Canadian Anesthesiologists' Society 2019

\begin{abstract}
Purpose Recent studies on patients with stable obesityhypoventilation syndrome have raised concerns about hyperoxia-induced hypercapnia in this population. This study aimed to evaluate whether a higher oxygen saturation target would increase arterial partial pressure of carbon dioxide $\left(\mathrm{PaCO}_{2}\right)$ in obese patients after coronary artery bypass grafting surgery $(C A B G)$.

Methods Obese patients having $C A B G$ were recruited. With a randomized crossover design, we compared two oxygenation strategies for $30 \mathrm{~min}$ each, immediately after extubation: a peripheral oxygen saturation $\left(\mathrm{SpO}_{2}\right)$ target of $\geq 95 \%$ achieved with manual oxygen titration (liberal) and a $\mathrm{SpO}_{2}$ target of $90 \%$ achieved with $\mathrm{FreeO}_{2}$, an automated oxygen titration device (conservative). The main outcome was end-of-period arterial $\mathrm{PaCO}_{2}$.

Results Thirty patients were included. Mean (standard deviation [SD]) body mass index (BMI) was 34 (3) $\mathrm{kg} \cdot \mathrm{m}^{-2}$ and mean (SD) baseline partial pressure of carbon dioxide
\end{abstract}

Electronic supplementary material The online version of this article (https://doi.org/10.1007/s12630-019-01500-x) contains supplementary material, which is available to authorized users.

M.-H. Denault, MD $(\varangle) \cdot$ C. Ruel, MD - M. Simon, MD P.-A. Bouchard, RT - S. Simard, MSc $\cdot$ F. Lellouche, PhD Institut universitaire de cardiologie et de pneumologie de Québec - Université Laval Research Center, 2725 Chemin Ste-Foy, Quebec, QC G1V 4G5, Canada

e-mail: marie-helene.denault.1@ulaval.ca
$\left(\mathrm{PCO}_{2}\right)$ was 40.7 (3.1) mmHg. Mean (SD) end-of-period $\mathrm{PaCO}_{2}$ was 42.0 (5.4) $\mathrm{mmHg}$ in the conservative period, compared with 42.6 (4.6) $\mathrm{mmHg}$ in the liberal period [mean difference - 0.6 (95\% confidence interval - 2.2 to 0.9) $\mathrm{mmHg}$; $P=0.4]$. Adjusted analysis for age, BMI, narcotics, and preoperative $\mathrm{PaCO}_{2}$ did not substantively change the results. Fourteen patients were retainers, showing an elevation in mean (SD) $\mathrm{PaCO}_{2}$ in the liberal period of 3.3 (4.1) $\mathrm{mmHg}$. Eleven patients had the opposite response, with a mean (SD) end-of-period $\mathrm{PaCO}_{2}$ decrease of 1.8 (2.2) $\mathrm{mmHg}$ in the liberal period. Five patients had a neutral response.

Conclusion This study did not show a clinically important increase in $\mathrm{PaCO}_{2}$ associated with higher $\mathrm{SpO}_{2}$ values in this specific population of obese patients after CABG. Partial pressure of carbon dioxide increased with liberal oxygen administration in almost half of the patients, but no predictive factor was identified.

Trial registration $w w w . c l i n i c a l t r i a l s . g o v \quad$ (NCT02917 668); registered 25 September, 2016.

Résumé

Objectif Des études récentes portant sur les patients atteints d'un syndrome obésité-hypoventilation stable ont soulevé des inquiétudes quant à l'hypercapnie induite par l'hyperoxie chez cette population. Notre étude avait pour objectif d'évaluer si une cible de saturation en oxygène plus élevée augmenterait la pression artérielle partielle de dioxyde de carbone $\left(\mathrm{PaCO}_{2}\right)$ chez des patients obèses après une chirurgie de pontages aortocoronariens (PAC). 
Méthode Des patients obèses listés pour une chirurgie de PAC ont été recrutés. À l'aide d'une méthodologie d'étude randomisée avec devis croisé, nous avons comparé deux stratégies d'oxygénation pendant $30 \mathrm{~min}$ chacune, immédiatement après l'extubation: une cible de saturation périphérique en oxygène $\left(\mathrm{SpO}_{2}\right)$ de $\geq 95 \%$ atteinte avec une titration d'oxygène manuelle (stratégie libérale), et une cible de $\mathrm{SpO}_{2}$ de $90 \%$ atteinte à l'aide d'un dispositif automatisé de titration de l'oxygène, $\mathrm{FreeO}_{2}$ (stratégie conservatrice). Le critère d'évaluation principal était la $\mathrm{PaCO}_{2}$ artérielle en fin de période d'étude.

Résultats Trente patients ont été inclus dans notre étude. L'indice de masse corporelle (IMC) moyen (écart type [ÉT]) était de $34(3) \mathrm{kg} \cdot \mathrm{m}^{-2}$ et la tension partielle moyenne (ÉT) de dioxyde de carbone $\left(\mathrm{PCO}_{2}\right)$ au départ était de 40,7 $(3,1) \mathrm{mmHg}$. La PaCO${ }_{2}$ moyenne (ÉT) à la fin de la période était de 42,0 $(5,4) \mathrm{mmHg}$ dans la période conservatrice, par rapport à 42,6 $(4,6) \mathrm{mmHg}$ dans la période libérale [différence moyenne - 0,6 (intervalle de confiance $95 \%$, - 2,2 à 0,9) $\mathrm{mmHg}$; $P=0,4$ ]. L'analyse ajustée pour tenir compte de l'âge, de l'IMC, des narcotiques et de la $\mathrm{PaCO}_{2}$ préopératoire n'a pas modifié les résultats de manière importante. Quatorze patients ont fait de la rétention de $\mathrm{CO}_{2}$, affichant une élévation de la $\mathrm{PaCO}_{2}$ moyenne (ÉT) pendant la période libérale de 3,3 (4,1) $\mathrm{mmHg}$. Onze patients ont manifesté une réaction contraire, affichant une réduction moyenne (ÉT) de la $\mathrm{PaCO}_{2}$ en fin de période de 1,8 (2,2) $\mathrm{mmHg}$ dans la période d'administration libérale.

Cinq patients ont eu une réponse neutre.

Conclusion Cette étude n'a pas démontré d'augmentation cliniquement significative de la $\mathrm{PaCO}_{2}$ associée à des valeurs plus élevées de $\mathrm{SpO}_{2}$ dans cette population spécifique de patients obèses après une chirurgie de PAC. La pression partielle de dioxyde de carbone a augmenté lors d'une administration libérale d'oxygène chez près de la moitié des patients, mais aucun facteur prédictif n'a été identifié.

Enregistrement de l'étude www.clinicaltrials.gov (NCT02917668); enregistrée le 25 septembre 2016.

Risks of hypercapnia induced by oxygen therapy have been recognized for almost 70 years. ${ }^{1-3}$ Indeed, hyperoxiainduced hypercapnia has been thoroughly documented in chronic obstructive pulmonary disease (COPD) patients, with a significant impact in the acute setting., ${ }^{3,4}$ Consequently, international guidelines recommend an oxygen saturation target of $88-92 \%$ for patients at risk of hypercapnia in this population. ${ }^{5-7}$
Obese patients may also be at risk for hyperoxia-induced hypercapnia, ${ }^{5,6}$ but the literature is sparse. Two small trials have been conducted in morbidly obese patients with obesity-hypoventilation syndrome (OHS) and an elevated baseline partial pressure of carbon dioxide $\left(\mathrm{PCO}_{2}\right)$. They have, respectively, shown a mean increase in $\mathrm{PCO}_{2}$ of 5 $\mathrm{mmHg}$ (transcutaneous) and $3.8 \mathrm{mmHg}$ after a 20-min exposure to hyperoxia. ${ }^{8,9}$ Weak recommendations for a peripheral capillary oxygen saturation $\left(\mathrm{SpO}_{2}\right)$ target of 88 92\% have been issued for selected patients such as the morbidly obese (grade D) ${ }^{5}$ and those with OHS (grade C). ${ }^{6}$

Whether hyperoxia-induced hypercapnia occurs in patients with milder obesity and without hypoventilation remains unknown. There is a gap in the literature concerning the impact in the acute setting as well. Meanwhile, obese patients represent no less than $41 \%$ of patients undergoing cardiac surgery ${ }^{10}$ and are known to have increased postoperative morbidity and mortality. ${ }^{10,11}$ Furthermore, hyperoxemia during and after cardiac surgery has been associated with coronary and systemic vasoconstriction, direct myocardial injury, and reduced cardiac index. ${ }^{12}$

This study aimed to test the hypothesis that a liberal oxygen saturation target $\geq 95 \%$ would be associated with higher $\mathrm{PaCO}_{2}$ values compared with a conservative oxygen saturation target of $90 \%$ in obese patients after coronary artery bypass grafting (CABG).

\section{Methods}

Study design and protocol

We conducted a single-centre randomized crossover trial at Quebec's Heart and Lung Institute between October 2016 and January 2018. This study was approved by our Institutional Review Board (IRB \#21366, September 15 2016) and written informed consent was obtained from all subjects participating in the trial. The trial was registered prior to patient enrollment at Clinicaltrials.gov (NCT02917668, Principal investigator: François Lellouche, Date of registration: September 25 2016). The manuscript adheres to the applicable CONSORT guidelines. ${ }^{13}$ Potentially eligible patients were prospectively screened through the cardiac surgery operating schedule by a research team member. Patients were invited to participate in the study the day before their procedure if they were obese (body mass index $[\mathrm{BMI}] \geq 30 \mathrm{~kg} \cdot \mathrm{m}^{-2}$ ) and scheduled for CABG as a sole intervention. The relatively low BMI criteria was chosen to include patients with mild and moderate obesity, as this was identified as a gap in the literature. Another inclusion criterion was a $\mathrm{SpO}_{2} \geq 95 \%$ before extubation. We excluded patients with either COPD, a restrictive 
syndrome other than one associated with obesity, or obstructive sleep apnea requiring continuous positive airway pressure (CPAP) to focus on obesity as a sole potential risk factor for hyperoxia-induced hypercapnia.

The trial was conducted in the post-cardiac surgery intensive care unit, starting within $30 \mathrm{~min}$ after extubation. Each patient took part in two consecutive 30-min periods in a randomized order: $\mathrm{SpO}_{2}$ target of $90 \pm 2 \%$ (conservative) achieved with automated oxygen flow titration by $\mathrm{FreeO}_{2}$ (Oxynov, Quebec City, QC, Canada), and a $\mathrm{SpO}_{2}$ target $\geq$ 95\% (liberal) achieved with routine manual oxygen flow titration by nurses as per local protocol. There was no wash-out period because of safety concerns, since most patients could not be completely weaned from oxygen therapy in this early postoperative state. Of note, in previous trials, a 20-min exposure to hyperoxia was sufficient to cause hypercapnia in patients with obesityhypoventilation syndrome ${ }^{8,9}$ and in patients with exacerbated COPD. ${ }^{14}$ The FreeO $_{2}$ device had been approved by Health Canada for research purposes (January 25 2017; approval \#260546) by the time the study started, and it is currently under evaluation for commercialization in Canada. It is an automatic oxygen titration device that relies on a closed-loop system, allowing oxygen flow to be adjusted every second according to the patient's real-time $\mathrm{SpO}_{2}$ and a target set by the physician on the controlling screen (eFig. 1 as Electronic Supplementary Material [ESM]). ${ }^{15} \mathrm{FreeO}_{2}$ has proven superior to manual titration for keeping patients within a saturation target. ${ }^{15-18} \mathrm{We}$ decided to use it in the conservative period only, to keep the liberal period as close to institutional protocol as possible. Non-rebreathing and Venturi masks were used for conservative and liberal periods respectively; neither non-invasive ventilation nor CPAP were applied during either study period. Bed head angulation was kept as constant as possible; only changes necessary for patient comfort were made by the nursing staff. All other aspects of patient care were based on institutional protocol. Protocol compliance was closely monitored by a research team member who remained at bedside for the whole protocol duration. Sequence randomization was computer generated by a research team member with randomization.org and concealment was preserved with opaque sealed envelopes. Neither the patients, the care providers, or the outcome assessors could be blinded because of the study design.

\section{Data collection}

A baseline capillary blood gas was obtained the day before surgery. On the study day, three arterial blood gases were drawn via arterial lines placed in the operating room: one before extubation and one after each study period. For the whole study, $\mathrm{FreeO}_{2}$ continuously recorded heart rate, $\mathrm{SpO}_{2}$, and oxygen flow with one value per second for each parameter. A Nonin oximeter embedded in the $\mathrm{FreeO}_{2}$ device provided non-averaged $\mathrm{SpO}_{2}$ values. FreeO ${ }_{2}$ was set in the closed-loop mode during the conservative period and in the recording mode during the liberal period. Respiratory rate, fraction of inspired oxygen $\left(\mathrm{F}_{\mathrm{I}} \mathrm{O}_{2}\right)$ (liberal period), arterial blood pressure, pulmonary artery pressure, as well as narcotics, vasopressor, and nitrate dosages were manually recorded by a research team member every ten minutes.

\section{Outcomes}

The primary outcome was end-of-period $\mathrm{PaCO}_{2}$. We defined as retainers the patients with any increase in $\mathrm{PaCO}_{2}$ during liberal oxygen administration. Secondary outcomes were end-of-period $\mathrm{pH}$ and partial oxygen pressure on arterial blood gas $\left(\mathrm{PaO}_{2}\right)$; the percentage of time spent within the $\mathrm{SpO}_{2}$ target value $(88-92 \%$ in conservative period and $\geq 95 \%$ in liberal period), with hypoxemia $\left(\mathrm{SpO}_{2}<88 \%\right)$, with severe hypoxemia $\left(\mathrm{SpO}_{2}<\right.$ $85 \%)$ and with hyperoxemia $\left(\mathrm{SpO}_{2}>96 \%\right)$ in each period; and hemodynamic parameters (arterial blood pressure, pulmonary artery pressure, vasopressor dosage, lactates) measured at ten-minute intervals.

\section{Statistical analyses}

Sample size was first empirically set to 15 patients, since there was no previous study on the effect of hyperoxia on obese patients in acute care. An interim analysis of 15 patients showed that half were retainers, with a mean increase in $\mathrm{PCO}_{2}$ of $4 \mathrm{mmHg}$ associated with liberal oxygen administration. In light of this tendency, the protocol was amended to increase the sample size to 30 patients to detect a $5-\mathrm{mmHg}$ difference in $\mathrm{PaCO}_{2}$ between periods, with a power of 0.80 and an alpha error of 0.05 .

Data were expressed as means (SD) to summarize baseline characteristics and outcomes. Sex and comorbidities were expressed as proportions. Continuous variables were analyzed using a mixed model. This statistical approach was involved to analyze a two-period crossover trial.

Estimated treatment comparison was obtained from a model with carry-over effect. Type I sum of square was used to perform tests on fixed effects in this order: carryover effect, treatment effect, and period effect. Whereas the adjustment had no effect on standard error of the estimated treatment differences, degrees-of-freedom calculations proposed by Kenward and Roger were involved. The normality assumption was verified with the Shapiro-Wilk test on the error distribution from the statistical model after 
a Cholesky factorization. The Brown and Forsythe's variation of Levene's test statistic was used to verify the homogeneity of variances. The $\mathrm{PaCO}_{2}$ at the end of 30-min periods (primary outcome) was analyzed after adjusting for age, BMI, baseline preoperative $\mathrm{PCO}_{2}$, and cumulative narcotics dosage before study entry as independent variables in a multivariable analysis. Four measurements were recorded for respiratory rate, $\mathrm{F}_{\mathrm{I}} \mathrm{O}_{2}$ (control period), arterial blood pressure, pulmonary artery pressure, as well as narcotics, vasopressor and nitrates dosages. These supplemental factors were analyzed as repeated factors with an autoregressive correlation structure among measurements. Interaction effects were investigated between these factors with the crossover model effects (three factors). The results were considered significant when $P$ values were $\leq 0.05$. All analyses were conducted using the statistical packages R v3.3.2 (R Foundation for Statistical Computing, Vienna, Austria) and SAS v9.4 (SAS Institute Inc, Cary, NC, USA).

\section{Results}

\section{Subjects}

The study was conducted between September 2016 and January 2018. Three hundred and sixty patients scheduled for CABG were screened, of which 30 were included and analyzed (Fig. 1). Subjects characteristics are shown in Table 1.

\section{Intervention}

Two groups with distinct oxygenation interventions were obtained. The mean (SD) $\mathrm{SpO}_{2}$ was 91 (1)\% in the conservative period and 97 (2)\% in the liberal period $(P<$ 0.001). The randomization consisted of 17 patients beginning with conservative oxygen administration and 13 patients beginning with liberal oxygen administration. Mean (SD) bed head angulation was 38 (6) and 37 (6) degrees in the liberal and conservative periods, respectively. It was kept constant ( \pm 2 degrees) between periods for $25 / 30$ patients.

\section{Primary outcome}

Arterial blood gases data were complete for all 30 included patients (Table 2 and Fig. 2). Mean (SD) end-of-period $\mathrm{PaCO}_{2}$ was 42.0 (5.4) $\mathrm{mmHg}$ in the conservative period, compared with 42.6 (4.6) $\mathrm{mmHg}$ in liberal period (mean difference, $-0.6 ; 95 \%$ confidence interval, -2.2 to 0.9 $\mathrm{mmHg} ; P=0.4)$. Multivariable analysis for age, BMI, baseline $\mathrm{PCO}_{2}$, and narcotics received before the start of the study resulted in an identical effect estimate. The only variable that had a significant interaction in the univariate analyses was baseline $\mathrm{PCO}_{2}$, but this became nonsignificant in the multivariable analysis. Since two patients did not reach a $\mathrm{SpO}_{2}$ of $95 \%$ in the liberal period, and electronic data were not logged for one patient, per-protocol analysis was conducted and showed no difference in the effect estimate (eTable 1 as ESM). A comparison of $\mathrm{PaCO}_{2}$ values for individual patients can be found in Fig. 2. Fourteen (47\%) patients were retainers, showing a higher end-of-period $\mathrm{PaCO}_{2}$ in the liberal period compared with the conservative period with a mean (SD) increase of 3.3 (4.0) $\mathrm{mmHg}$ (eTable 2 as ESM; Fig. 2). Eleven $(37 \%)$ patients had the opposite response, with a lower end-of-period $\mathrm{PaCO}_{2}$ in the liberal period that decreased by $1.8(2.2) \mathrm{mmHg}$. Five (17\%) patients did not show any change in end-of-period $\mathrm{PaCO}_{2}$. Looking at the $\mathrm{PaCO}_{2}$ change from baseline, the mean (SD) change in $\mathrm{PaCO}_{2}$ was 0.9 (4.3) $\mathrm{mmHg}$ in the liberal period, compared with -0.6 (4.2) $\mathrm{mmHg}$ in the conservative period. Despite the crossover design, the sequence effect never had an observed $P$ value below 0.15 , and thus did not affect the results.

\section{Secondary outcomes}

There was no difference in $\mathrm{pH}$ or bicarbonate concentration between the two study periods (Table 2), except for slight decreases in the retainers' population in the liberal period (eTable 2 as ESM). Pulse oximetry data recorded by FreeO $_{2}$ were available for 29 patients (Table 2 and Fig. 3). Electronic data of one patient were not logged. FreeO maintained the patients within the conservative $\mathrm{SpO}_{2}$ target for 73 (4)\% of the time. Considering the time when oxygen flow rate was $>0 \mathrm{~L} \cdot \mathrm{min}^{-1}$ only, this percentage (SD) rose to 82 (22)\%, compared with 84 (27)\% during the liberal period. During the conservative period, the percentage of time spent in hypoxemia $\left(\mathrm{SpO}_{2}<88 \%\right)$ slightly increased $(P=0.04)$, while the percentage of time spent in hyperoxemia $\left(\mathrm{SpO}_{2}>96 \%\right)$ markedly decreased $(P<$ 0.001). eFigure 2 (available as ESM) shows the oxygenation profiles (oxygen saturation, flow, and $\mathrm{F}_{\mathrm{I}} \mathrm{O}_{2}$ ) over time during conservative and liberal oxygen administration for a typical patient.

Hemodynamic parameters were available for all 30 patients, except for a single missing serum lactate measurement and heart rate values for one patient, whose electronic data were not logged. A reduction in systemic blood pressure was noted after the conservative oxygenation period (Table 3), with a significant period effect that was not correlated to narcotics or nitrates dosage, nor change in $\mathrm{PaCO}_{2}$. No difference in vasopressor 


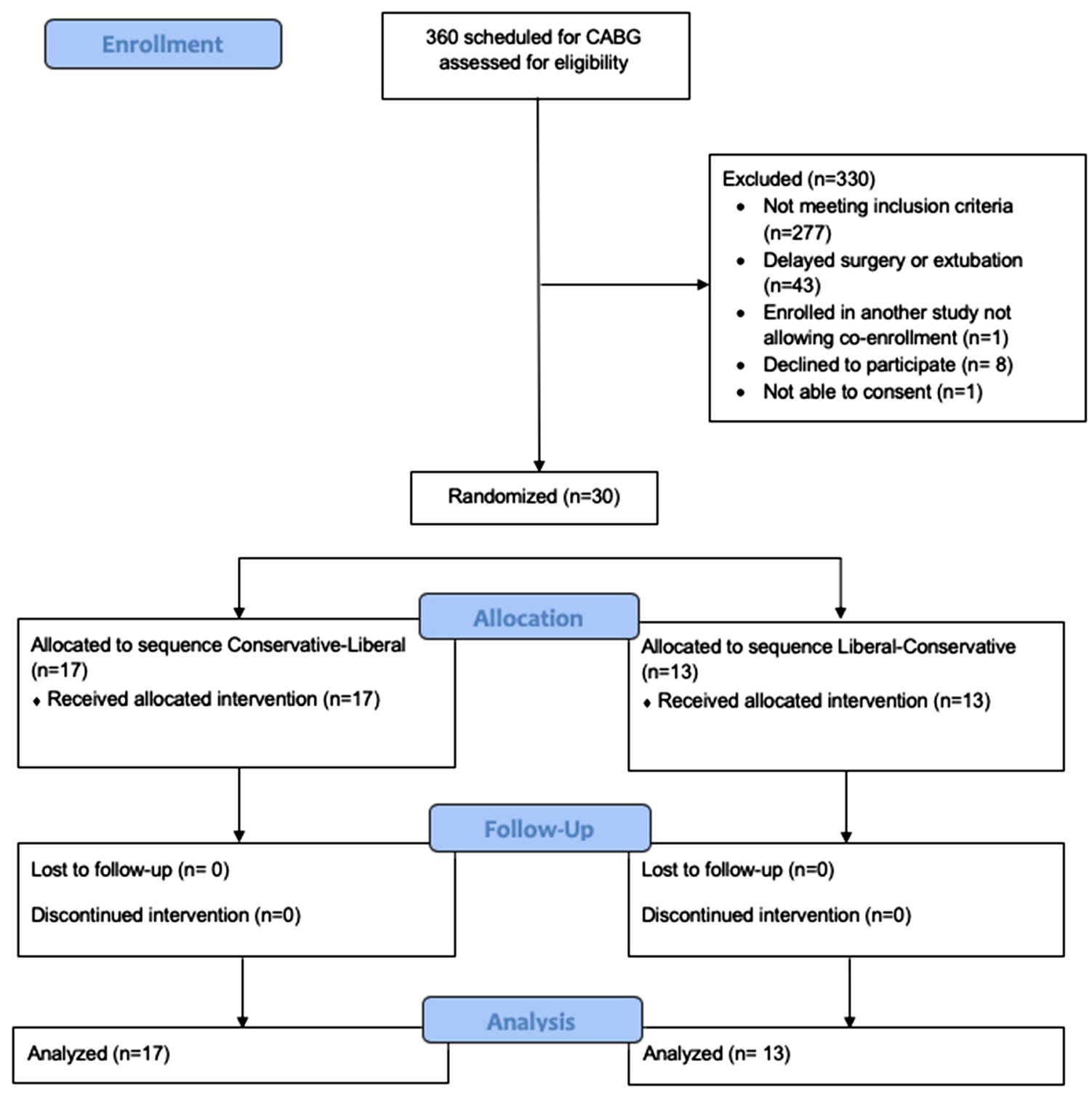

Fig. 1 Patient selection flow chart. $\mathrm{CABG}=$ coronary artery bypass grafting

dosage resulted. Heart rate, pulmonary artery pressures, and lactates did not change significantly.

\section{Discussion}

This is the first trial to evaluate the risk of hyperoxiainduced hypercapnia in mildly to moderately obese cardiac surgery patients. We did not find a clinically important increase of $\mathrm{PaCO}_{2}$ in response to liberal oxygen administration in obese patients without other risk factors for hypoventilation, as opposed to results from two previous studies on OHS patients. $^{8,9}$ This might be explained by several factors, namely a lower mean BMI of $33.6 \mathrm{~kg} \cdot \mathrm{m}^{-2}$ compared with $52.4 \mathrm{~kg} \cdot \mathrm{m}^{-2}$ and $53 \mathrm{~kg} \cdot \mathrm{m}^{-2}$ in the two previous studies on OHS patients, ${ }^{8,9}$ as well as moderate hyperoxia and a short duration of the exposure. Mean $\mathrm{F}_{\mathrm{I}} \mathrm{O}_{2}$ was $58.6 \%$ in the present study compared with $100 \%$ in Wijesinghe's study, which showed the greatest $\mathrm{PaCO}_{2}$ increase induced by hyperoxemia. Wijesinghe and al. studied 20 subjects with stable obesity-associated hypoventilation, comparing a $\mathrm{F}_{\mathrm{I}} \mathrm{O}_{2}$ of $21 \%$ and $100 \%$ for 20 min each, and showed a mean increase in transcutaneous tension of $\mathrm{CO}_{2}$ of $5 \mathrm{mmHg}$ in the hyperoxia period. ${ }^{8}$ The $\mathrm{PaCO}_{2}$ rise noted in retainers during liberal oxygen administration in the present study is similar to the overall mean difference observed in another trial, which exposed 28 stable OHS patients to a $\mathrm{F}_{\mathrm{I}} \mathrm{O}_{2}$ of $28 \%$ and $50 \%$ for 20 min each. ${ }^{9}$

The percentage of time spent within oxygenation target with $\mathrm{FreeO}_{2}$ was lower than what was observed in previous studies on patients with acute respiratory failure in the 
Table 1 Subjects

characteristics at baseline $(n=$ 30)

Data are presented as means (standard deviation), unless stated otherwise

$\mathrm{BMI}=$ body mass index $; \mathrm{F}_{1} \mathrm{O}_{2}=$ fraction of inspired oxygen; $\mathrm{PaCO}_{2}=$ partial pressure in carbon dioxide (arterial blood gas); $\mathrm{PaO}_{2}=$ partial oxygen pressure (arterial blood gas); $\mathrm{PCO}_{2}=$ partial pressure in carbon dioxide (capillary blood gas); PEEP = positive endexpiratory pressure; $\mathrm{SpO}_{2}=$ peripheral oxygen saturation

\begin{tabular}{ll}
\hline Characteristic & Value \\
\hline Age $(\mathrm{yr})$ & $62(9)$ \\
$\mathrm{Sex}($ number of males) & $23 / 30$ \\
$\mathrm{BMI}\left(\mathrm{kg} \cdot \mathrm{m}^{-2}\right)$ & $34(3)$ \\
Comorbidities $(n)$ & \\
Hypertension & 25 \\
Dyslipidemia & 14 \\
Diabetes mellitus & 9 \\
Heart failure & 7 \\
Chronic kidney disease & 7 \\
Number of coronary grafts $(n)$ & $4(1)$ \\
Preoperative $\mathrm{PCO}_{2}(\mathrm{mmHg})$ & $40.7(3.1)$ \\
Pre-extubation $\mathrm{PaCO}_{2}(\mathrm{mmHg})$ & $42.3(5.5)$ \\
Pre-extubation $\mathrm{PaO}_{2}(\mathrm{mmHg})$ & $104(49)$ \\
Pre-extubation $\mathrm{SpO}_{2}(\%)$ & $97(2)$ \\
Pre-extubation $\mathrm{F}_{\mathrm{l}} \mathrm{O}_{2}(\%)$ & $37(7)$ \\
Pre-extubation $\left.\mathrm{PEEP}^{(\mathrm{cmH}}{ }_{2} \mathrm{O}\right)$ & $6(2)$ \\
Cumulative narcotics before study entry $(\mu \mathrm{g}$ of fentanyl) & $1931(760)$ \\
\hline
\end{tabular}

Table 2 Arterial blood gases and oxygenation during the two study conditions (intention-to-treat analysis; $n=30$ )

\begin{tabular}{|c|c|c|c|c|}
\hline & $\begin{array}{l}\text { Conservative } \\
\left(\mathrm{SpO}_{2} \text { target }=90 \%\right)\end{array}$ & $\begin{array}{l}\text { Liberal } \\
\left(\mathrm{SpO}_{2} \geq 95 \%\right)\end{array}$ & $\Delta$ Conservative-Liberal & $P$ value \\
\hline $\mathrm{pH}$ & $7.35(0.04)$ & $7.35(0.04)$ & $0.00(-0.01$ to 0.01$)$ & 0.68 \\
\hline $\mathrm{PaCO}_{2}(\mathrm{mmHg})$ & $42.0(5.4)$ & $42.7(4.6)$ & $-0.6(-2.2$ to 0.9$)$ & 0.41 \\
\hline $\mathrm{HCO}_{3}\left(\mathrm{meq} \cdot \mathrm{L}^{-1}\right)$ & $22.3(2.2)$ & $22.8(2.2)$ & $-0.4(-1.0$ to 0.1$)$ & 0.10 \\
\hline $\mathrm{PaO}_{2}(\mathrm{mmHg})$ & $73(6)$ & $118(32)$ & $-46(-58$ to -33$)$ & $<0.001$ \\
\hline $\mathrm{RR}$ (breaths $\cdot \min ^{-1}$ ) & $21(7)$ & $21(6)$ & $0(0$ to 1$)$ & 0.30 \\
\hline $\mathrm{SpO}_{2}(\%)$ & $91(1)$ & $97(2)$ & $-6(-6$ to -5$)$ & $<0.001$ \\
\hline $\mathrm{O}_{2}$ flow $\left(\mathrm{L} \cdot \mathrm{min}^{-1}\right)$ & $0.9(1.0)^{*}$ & - & - & - \\
\hline $\mathrm{F}_{\mathrm{I}} \mathrm{O}_{2}(\%)$ & - & $59 * *(21)$ & - & - \\
\hline
\end{tabular}

Data are presented as means (standard deviation) except for differences, which are presented as mean differences (95\% confidence interval) $\mathrm{FIO}_{2}=$ fraction of inspired oxygen; $\mathrm{HCO}_{3}=$ serum bicarbonates; $\mathrm{PaCO}_{2}=$ partial pressure in carbon dioxide; $\mathrm{PaO}_{2}=$ partial pressure in oxygen; $\mathrm{RR}=$ respiratory rate (manual measurement); $\mathrm{SpO}_{2}=$ peripheral oxygen saturation

$\mathrm{SpO}_{2}$ and $\mathrm{O}_{2}$ flow rates are based on $\mathrm{FreeO}_{2}$ continuous recordings

*Equivalent to $\mathrm{F}_{1} \mathrm{O}_{2}<24 \%$

**Equivalent to approximately $9 \mathrm{~L} \cdot \mathrm{min}^{-1}$

emergency room $(81.3 \%)^{17}$ and patients hospitalized for an acute exacerbation of COPD $(81.2 \%)^{18}$ mainly because of an increase in the percentage of time spent above the $\mathrm{SpO}_{2}$ target while patients did not require any supplemental oxygen. This reflects the overall minimal oxygen requirements of our population to meet the $\mathrm{SpO}_{2}$ target of $88-92 \%$. The percentage of time spent within target when $\mathrm{FreeO}_{2}$ was giving oxygen only was closer to the percentages seen in previous studies. ${ }^{17,18}$
A slight reduction in blood pressure was associated with lower $\mathrm{SpO}_{2}$ in the conservative oxygen administration period, which was an unexpected finding. This was not clinically significant since no increase in vasopressor requirements nor adverse outcomes occurred during the observation period. A period effect was found for systolic blood pressure only, which was probably due to chance given the small sample size. A similar effect of conservative oxygenation has been observed in a trial on oxygen therapy in myocardial infarction, ${ }^{19}$ in which a 


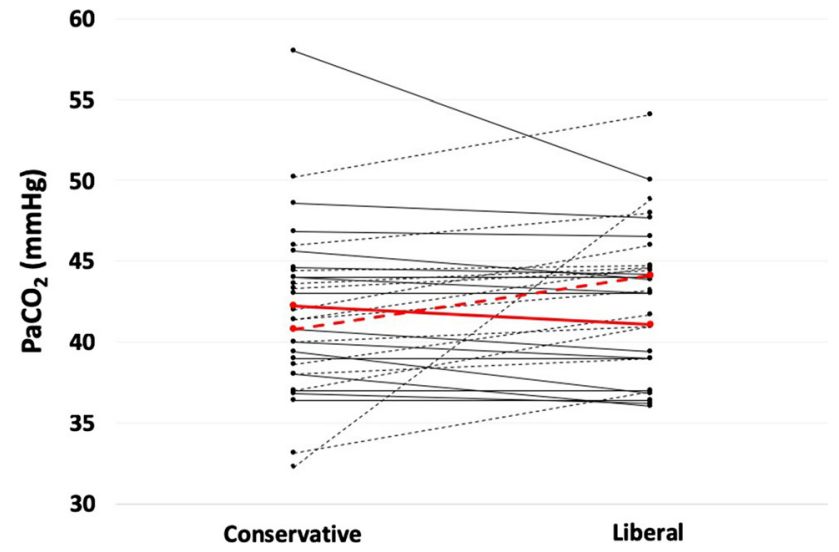

Fig. 2 Mean $\mathrm{PaCO}_{2}$ at the end of each period for individual patients. Data of retainers are presented with black dotted lines and data of non-retainers are presented with black solid lines. Mean values are presented in red. $\mathrm{PaCO}_{2}=$ partial pressure in $\mathrm{CO}_{2}$ (arterial blood gas)

higher percentage of patients received intravenous inotropes in the ambient air group than in the oxygen group (2.1 vs $1.4 \%, P=0.02)$. This might come from increased nitrous oxide (NO) production and systemic vasodilatation caused by hypoxemia, while hyperoxemia has been linked to decreased NO production and an increase in systemic resistances. ${ }^{20} \mathrm{~A} \mathrm{SpO}_{2}$ target of $92 \%$ or 94\% might be safer in obese patients after cardiac surgery, given the absence of induced hypercapnia with $\mathrm{SpO}_{2}$ above 95\% and a possible detrimental effect of hypotension after CABG, but this is only speculative since we achieved moderate hyperoxia.
Strengths of this study include the crossover design, which allowed comparison of two groups, the population homogeneity, and the protocol compliance with constant bedside monitoring of the procedures. The protocol was completed for all 30 patients and there were very few missing data. We examined all available plausible factors to better characterize retainers and non-retainers but did not find any. This study compared two well separated oxygenation targets and it was possible to prove with continuous $\mathrm{SpO}_{2}$ monitoring that patients remained within oxygenation target range more than $80 \%$ of the time in both groups. The use of automated oxygen titration is another methodological strength of the study.

There are several limitations to the study. A type II error is possible because of the small sample size, the moderate hyperoxia to which the patients were exposed, and the short duration of the study. Nonetheless, a 20-min exposure to hyperoxia was sufficient to cause hypercapnia in previous trials. ${ }^{8,9,14}$ Of note, the crossover design precluded longer study periods because of the rapidly evolving postoperative state. Also, systematic preoperative spirometry and polysomnography could have provided further insight into the characteristics of retainers. Furthermore, the study was not blinded, so differential nursing care could have occurred between periods. Finally, this was a carefully selected population and extrapolation is limited.

This trial showed that moderate hyperoxia in postoperative obese patients without risk factors for hypoventilation does not affect short-term outcomes. Moreover, the results do not support a strict $88-92 \%$ saturation target in this population. More studies are

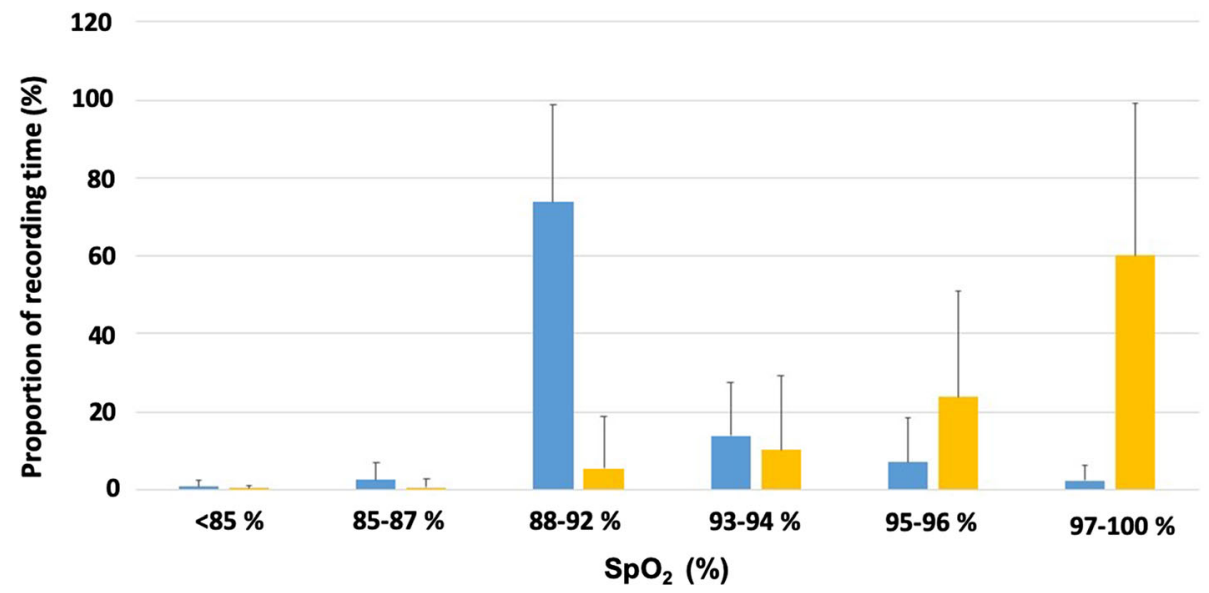

Fig. 3 Mean percentage of time spent within different saturation ranges in the different study periods. Conservative period is represented in blue $\left(\mathrm{SpO}_{2}\right.$ target $\left.90 \pm 2 \%\right)$ and liberal period $\left(\mathrm{SpO}_{2}\right.$ target $\geq 95 \%$ ) in yellow bands. Black bars are standard deviations. Constant $\mathrm{SpO}_{2}$ monitoring and recording were done by $\mathrm{FreeO}_{2}$ with

one value per second, using the $\mathrm{FreeO}_{2}$ with Nonin oximeter embedded. The device was set in $\mathrm{FreeO}_{2}$ mode (conservative period) or recording mode (liberal period). $\mathrm{SpO}_{2}=$ peripheral oxygen saturation 
Table 3 Hemodynamic parameters during the two study conditions $(n=30)$

\begin{tabular}{|c|c|c|c|c|}
\hline & $\begin{array}{l}\text { Conservative } \\
\left(\mathrm{SpO}_{2}=90 \%\right)\end{array}$ & $\begin{array}{l}\text { Liberal } \\
\left(\mathrm{SpO}_{2} \geq 95 \%\right)\end{array}$ & $\Delta$ Conservative-Liberal & $P$ value \\
\hline $\mathrm{SBP}(\mathrm{mmHg})$ & $112(15)$ & $118(16)$ & $-6(-10$ to -2$)$ & 0.002 \\
\hline $\mathrm{DBP}(\mathrm{mmHg})$ & $63(7)$ & $67(8)$ & $-4(-6$ to -2$)$ & $<0.001$ \\
\hline $\mathrm{MBP}(\mathrm{mmHg})$ & $79(9)$ & $83(10)$ & $-5(-8$ to -2$)$ & 0.002 \\
\hline sPAP $(\mathrm{mmHg})$ & $33(7)$ & $32(7)$ & $1(-1$ to 2$)$ & 0.49 \\
\hline $\mathrm{dPAP}(\mathrm{mmHg})$ & $17(5)$ & $18(6)$ & $-1(-2$ to 0$)$ & 0.13 \\
\hline mPAP $(\mathrm{mmHg})$ & $23(6)$ & $23(6)$ & $0(-1$ to 1$)$ & 0.88 \\
\hline HR (beats $\cdot \min ^{-1}$ ) & $90(11)$ & $90(11)$ & $0(-1$ to 1$)$ & 0.92 \\
\hline Lactates $\left(\mathrm{mmol} \cdot \mathrm{L}^{-1}\right)$ & $1.9(1.0)$ & $1.9(1.1)$ & $0.1(0.0$ to 0.1$)$ & 0.17 \\
\hline Noradrenaline dosage $\left(\mu \mathrm{g} \cdot \mathrm{kg}^{-1}\right) \cdot \mathrm{min}^{-1}$ & $0(0)$ & $0(0)$ & $0(0$ to 0$)$ & 0.74 \\
\hline
\end{tabular}

Data are presented as means (standard deviation), except for differences, which are presented as mean differences (95\% confidence interval) $\mathrm{DBP}=$ diastolic blood pressure; $\mathrm{dPAP}=$ diastolic pulmonary artery pressure $; \mathrm{HR}=$ heart rate; $\mathrm{MBP}=$ mean blood pressure; $\mathrm{mPAP}=$ mean pulmonary artery pressure; $\mathrm{SBP}=$ systolic blood pressure; $\mathrm{SPAP}=$ systolic pulmonary artery pressure; $\mathrm{SpO}_{2}=$ peripheral oxygen saturation

needed to clarify the risk of acute hyperoxia-induced hypercapnia in obese patients with higher BMIs or risk factors for hypoventilation. The impact of higher levels and longer duration of hyperoxia should also be investigated in future trials.

Conflicts of interest Mathieu Simon is a shareholder and administrator of Oxynov, the company that developed and is commercializing $\mathrm{FreeO}_{2}$. François Lellouche is a co-founder, shareholder, and administrator of Oxynov. He co-invented the $\mathrm{FreeO}_{2}$ device used in this study. François Lellouche receives financial support from the Canada Foundation for Innovation (Research program for automation of ventilation and oxygenation). Marie-Hélène Denault, Carolanne Ruel, Pierre-Alexandre Bouchard and Serge Simard declare no competing interests.

Editorial responsibility This submission was handled by Dr. Philip M. Jones, Associate Editor, Canadian Journal of Anesthesia.

Authors contributions Marie-Hélène Denault had full access to the data during the study and takes responsibility for data accuracy and study safety. Marie-Hélène Denault designed the study, wrote the protocol, contributed to data collection and analysis, and wrote the manuscript. Carolanne Ruel contributed to data collection. Mathieu Simon contributed to study design and reviewed the manuscript. Pierre-Alexandre Bouchard contributed to study design, data collection, and data analysis. Serge Simard oversaw the statistical analyses. François Lellouche designed the study, reviewed the protocol, and reviewed the manuscript.

Funding Support was provided solely from institutional sources.

\section{References}

1. Beasley $R$, Patel M, Perrin K, O'Driscoll BR. High-concentration oxygen therapy in COPD. Lancet 2011; 378: 969-70.
2. Aubier M, Murciano D, Fournier M, Milic-Emili J, Pariente $R$, Derenne JP. Central respiratory drive in acute respiratory failure of patients with chronic obstructive pulmonary disease. Am Rev Respir Dis 1980; 122: 191-9.

3. Aubier M, Murciano D, Milic-Emili J, et al. Effects of the administration of $\mathrm{O} 2$ on ventilation and blood gases in patients with chronic obstructive pulmonary disease during acute respiratory failure. Am Rev Respir Dis 1980; 122: 747-54.

4. Austin MA, Wills KE, Blizzard L, Walters EH, Wood-Baker R. Effect of high flow oxygen on mortality in chronic obstructive pulmonary disease patients in prehospital setting: randomised controlled trial. BMJ 2010; DOI: https://doi.org/10.1136/bmj. c5462.

5. O'Driscoll BR, Howard LS, Earis J, Mak V; British Thoracic Society Emergency Oxygen Guideline Group; BTS Emergency Oxygen Guideline Development Group. BTS guideline for oxygen use in adults in healthcare and emergency settings. Thorax 2017; 72(Suppl 1): ii1-90.

6. Beasley $R$, Chien J, Douglas J, et al. Thoracic Society of Australia and New Zealand oxygen guidelines for acute oxygen use in adults: 'Swimming between the flags'. Respirology 2015; 20: 1182-91.

7. Rabe KF, Hurd S, Anzueto A, et al. Global strategy for the diagnosis, management, and prevention of chronic obstructive pulmonary disease: GOLD executive summary. Am J Respir Crit Care Med 2007; 176: 532-55.

8. Wijesinghe $M$, Williams $M$, Perrin $K$, Weatherall M, Beasley R. The effect of supplemental oxygen on hypercapnia in subjects with obesity-associated hypoventilation: a randomized, crossover, clinical study. Chest 2011; 139: 1018-24.

9. Hollier CA, Harmer AR, Maxwell LJ, et al. Moderate concentrations of supplemental oxygen worsen hypercapnia in obesity hypoventilation syndrome: a randomised crossover study. Thorax 2014; 69: 346-53.

10. Ghanta RK, LaPar DJ, Zhang Q, et al. Obesity increases riskadjusted morbidity, mortality, and cost following cardiac surgery. J Am Heart Assoc 2017; DOI: https://doi.org/10.1161/JAHA.116. 003831.

11. Choban PS, Flancbaum L. The impact of obesity on surgical outcomes: a review. J Am Coll Surg 1997; 185: 593-603.

12. Spoelstra-de-Man AM, Smit B, Oudemans-van Straaten HM, Smulders YM. Cardiovascular effects of hyperoxia during and after cardiac surgery. Anaesthesia 2015; 70: 1307-19. 
13. Schulz KF, Altman DG, Moher D; CONSORT Group. CONSORT 2010 statement: updated guidelines for reporting parallel group randomised trials. BMJ 2010; DOI: https://doi.org/10.1136/bmj. c332

14. Robinson TD, Freiberg DB, Regnis JA, Young IH. The role of hypoventilation and ventilation-perfusion redistribution in oxygen-induced hypercapnia during acute exacerbations of chronic obstructive pulmonary disease. Am J Respir Crit Care Med 2000; 161: 1524-9.

15. Lellouche F, L'Her E. Automated oxygen flow titration to maintain constant oxygenation. Respir Care 2012; 57: 1254-62.

16. Lellouche F, L'Her E, Bouchard PA, Brouillard C, Maltais F. Automatic oxygen titration during walking in subjects with COPD: a randomized crossover controlled study. Respir Care 2016; 61: 1456-64.

17. L'Her E, Dias P, Gouillou M, et al. Automatisation of oxygen titration in patients with acute respiratory distress at the
Emergency Department. A multicentric international randomized controlled study. Am J Respir Crit Care Med 2015; 191: A6329 (abstract).

18. Lellouche F, Bouchard PA, Roberge M, et al. Automated oxygen titration and weaning with FreeO2 in patients with acute exacerbation of COPD: a pilot randomized trial. Int J Chron Obstruct Pulmon Dis 2016; 11: 1983-90.

19. Hofmann R, James SK, Jernberg T, et al. Oxygen therapy in suspected acute myocardial infarction. N Engl J Med 2017; 377 : 1240-9.

20. Duling BR. Microvascular responses to alterations in oxygen tension. Circ Res 1972; 31: 481-9.

Publisher's Note Springer Nature remains neutral with regard to jurisdictional claims in published maps and institutional affiliations. 